\title{
MULHERES DAS ROCAS: IMERSÃO DO DOCUMENTÁRIO NO ESPAÇO- TEMPO DOS PERSONAGENS DO SAMBA EM NATAL/RN ROCAS'S WOMEN: IMMERSION OF THE DOCUMENTARY IN SPACE AND TIME OF SAMBA CHARACTERS IN NATAL, BRAZIL
}

\section{Lisabete Coradini}

lisabetecoradini@hotmail.com

Professora titular do Departamento de Antropologia - PPGAS, Navis - Núcleo de Antropologia Visual da Universidade Federal do Rio Grande do Norte (UFRN).

\section{Maria Angela Pavan}

gelpavan@gmail.com

Professora do Departamento de Comunicação Social e do PPGEM da Universidade Federal do Rio Grande do Norte (UFRN).

\section{RESUMO}

Este artigo traz uma reflexão sobre o método na construção do documentário $A s$ mulheres das Rocas são as vozes do samba. As mulheres das Rocas (bairro popular) são as guardiãs das memórias do samba local - além de detentoras da história, têm papel ativo desde o início na construção das escolas de samba em Natal (RN). Para realizar o documentário nos envolvemos com os acontecimentos locais durante quatro anos; desta forma, construímos um arquivo de fatos e entrevistas para documentação da história do samba, e entre lembranças, fotos, imagens e músicas, o audiovisual permitiu nos relacionarmos de forma intensa no espaço-tempo de cada entrevistada, que possibilitou conhecimento ativo na vida das mulheres do samba das Rocas. Descrevemos neste artigo o método utilizado, nossas pesquisas, leituras e reflexões, buscando as abordagens teóricas sobre a etnografia da duração de Eckert e Rocha e de MacDougall; e sobre a perspectiva de resgate das memórias de Sarlo e de Nora.

Palavras-chave: Narrativas. Memórias. Itinerários. Produção de sentido. Antropologia audiovisual.

\begin{abstract}
This paper shall reflect on the construction method used in the documentary As mulheres das Rocas são as vozes do samba. Rocas's Women (a popular neighborhood in Northeast Brazil) are memory guardians of the local samba. Besides being history owners, they have an active role since the beginning of Natal's ( $\mathrm{RN}$, Brazil) samba schools foundation. To do this documentary we were involved with local events for four years. This was a way to construct an archive of facts and interviews to the samba history documentation. Among memories, photographs, pictures and songs that we were able to relate with the space-time of each interviewed woman, the audiovisual allowed the creation of this intense relation and made an active knowledge about life of samba women from Rocas possible. In this
\end{abstract}


study we describe the used methodology, our researches, readings and reflections, based on the theoretical approach of the length of time ethnography, of Eckert and Rocha and MacDougall; and also on the rescue perspective of memories of Sarlo and Nora.

Keywords: Narratives. Memories. Itineraries. Meaning production. Visual and Media Anthropology.

Why and for whom do we put the camera amongst people? Strangely enough, my first response to this will always be the same: "for myself"

Jean Rouch

\section{COMEÇO}

Este artigo é uma reflexão sobre o intenso contato etnográfico desenvolvido no bairro das Rocas, com os moradores ligados ao universo do samba, entre os anos 2012 e 2016. Trata-se de uma discussão sobre o "fazer audiovisual" em uma comunidade que reivindica ser o berço do samba natalense. Apesar de não se ter ainda uma data precisa quanto ao surgimento do samba na cidade de Natal, devido às divergências existentes entre as diferentes fontes de pesquisa (entrevistas, jornais, artigos e teses), constatamos que o samba foi impulsionado nas primeiras décadas do século XX.

Apesar de o samba não ter território específico, é uma manifestação cultural que está associada a determinadas práticas sociais realizadas em bairros ou comunidades, fortalecendo a identidade de determinado lugar. O bairro das Rocas é considerado o berço do samba e se situa na área central de Natal, onde há resquícios da fundação da cidade, junto dos bairros Ribeira e Cidade Alta. Havia segregação espacial entre a Cidade Alta e a Cidade Baixa. Até meados do século passado, a Cidade Baixa era uma região de portuários, estivadores, ferroviários, pescadores, funcionários públicos e boêmios. Ali encontramos sedes das três mais importantes escolas de samba, que durante o carnaval movimentam os barracões. As baterias dessas agremiações promovem ensaios abertos diários, e esquentam seus tamborins, caixas, surdos, ganzás, repiques e chocalhos.

Historicamente, as festividades carnavalescas aconteciam nos bairros da Cidade Alta, hoje nos bairros Petrópolis e Tirol; e na Cidade Baixa, onde se encontra a Ribeira. Nos anos 1940, o samba ganha expressão, e a partir daí vários grupos começam a se organizar nos moldes das escolas de samba do Rio de Janeiro. Na década de 1960, surgem as primeiras escolas de samba, com destaque para os dirigentes que respondiam pelos problemas da escola. Em 1984, um evento trágico marcou a história do samba - um grave acidente envolvendo o bloco Puxa Saco provocou a morte de 22 integrantes. Esse fato foi amplamente divulgado nos jornais locais, apontando para um suposto declínio do carnaval na cidade. A partir de 1980, ao contrário do que se previa, inicia-se uma nova fase com a participação de trios elétricos, mas que não teve grande repercussão. $\mathrm{Na}$ década de 1990, a Prefeitura de Natal inova o carnaval, na tentativa de reinventar tradições, criando polos carnavalescos, entre eles, o polo da Ribeira.

Atualmente o carnaval acontece na Avenida Duque de Caxias, no bairro da Ribeira, e congrega diferentes escolas de diversos bairros e tribos de índios (representação performática de um drama da cultura indígena), movimenta a economia local (ambulantes, comércio informal, costureiras e alguns bares) e enfrenta o descaso das políticas públicas. No entanto, além dessas questões mencionadas, o carnaval aciona laços afetivos de subjetividades, de vizinhança e parentesco.

Nosso primeiro contato para a realização do documentário foi com o mestre Zorro, pedreiro de profissão, negro, alto, fala articulada e fluida. Nosso 
objetivo inicial era realizar uma videobiografia. Mas, logo após a primeira entrevista, ele nos desafiou a conhecer a cena do samba em Natal: "quero apresentar pessoas que jamais seriam entrevistadas, elas viveram o samba e o início das escolas de samba em Natal".

Como o encontro é feito de relações, uma das premissas é a escuta. Antropologia e Comunicação Social são a arte da escuta. Prestamos muita atenção no ritmo das palavras do mestre Zorro, não só nas entrevistas, como nas letras que compõe e nas rodas de samba das quais participa. Esse tipo de compromisso de representar o outro de maneira honesta em toda sua complexidade é algo possível, como nos ajuda David MacDougall $(1999$, p. 6) nesta reflexão:

\begin{abstract}
Uma coisa que eu faço é questionar e tentar conhecer quais são os interesses dos outros, o que é uma espécie de metodologia para lidar com outros interesses ali presentes. É importante para o cineasta reconhecer quais são os interesses presentes, uma vez que as pessoas podem mudar seu filme para demandas específicas. Em muitos casos, o fato do cineasta estar realizando um filme é um catalisador que abre oportunidades para que as pessoas da comunidade falem sobre elas, entre elas mesmas e para outros públicos, o que lhes confere certo poder, por exemplo, ao fazer suas reclamações por terras, leis de propriedade etc.
\end{abstract}

Gravar e entrar na história de um lugar é compreender quais são suas temporalidades, anseios e desejos - deixamos de lado nossa vida e nos entregamos à vida do novo espaço. Sem dúvida documentar é um ato de entrega, envolvimento e negociações entre quem fala e quem escuta; uma relação de compromisso e confiança constante. Os métodos da pesquisa foram sendo recriados durante o trabalho de campo. Foi preciso observar, entrar nas casas e ouvir as narrativas. As estratégias metodológicas e as técnicas de entrevistas pela câmera (captação de áudio, vídeo e som) são de levar em consideração a voz dos sujeitos investigados. A entrevista e a história de vida não foram os únicos procedimentos adotados. Como o pesquisador Muniz Sodré (2006) salienta, este exemplo permite verificar vínculos sensíveis na vida das pessoas. Em um segundo momento, passamos a frequentar as três escolas de samba sediadas no bairro - Malandros do Samba, Balanço do Morro e Em Cima da Hora - e os desfiles das escolas de samba durante o carnaval. Participamos de vários eventos relacionados ao samba local (desde "segunda da ressaca", nas segundas-feiras; passando pelo samba na Praça André de Albuquerque nas quintas até o samba no bar da Nazaré nos sábados à tarde).

Buscamos escrever sobre os espaços de convivência entre o pesquisador e os interlocutores; e neste artigo falaremos um pouco da nossa experiência e do método utilizado na construção do documentário.

Essa reflexão sobre usos da imagem na investigação em Antropologia e Comunicação (filme etnográfico, documentário, cinema observacional) e, principalmente, sobre o desenvolvimento de metodologias audiovisuais participativas e interativas foi aprofundada nas discussões dentro dos grupos de pesquisa².

Nossa primeira percepção foi sendo recriada a partir dessa vivência em campo. A incursão nos itinerários pouco percorridos revelou muitos estigmas e estereótipos ainda presentes na sociedade e, ao mesmo tempo, muita delicadeza, beleza e leveza das inúmeras histórias ouvidas.

\title{
O SAMBA
}

Como apontado anteriormente, o samba nasceu nas Rocas, um dos bairros mais antigos de Natal, outrora lugar de pescadores e operários. Esse bairro começa 
a se desenvolver em meados de 1920 com a construção de obras e equipamentos urbanos; e se moderniza nas décadas de 1950 e 1960, com a construção de casas ou de fachadas reformadas seguindo o estilo modernista da época. Atualmente o bairro acolhe diferentes manifestações culturais, como carnaval, tribos indígenas, futebol, a velha guarda do samba, grupos de danças, terreiros e igrejas. Nele há pontos de encontros como o Bar do Jonas, Bar da Naná, Racing Sport Club, a feira, o mercado e as escolas de samba Balanço do Morro, Malandros do Samba e Em Cima da Hora. Lugares de memórias e de sociabilidades, frequentados pelos moradores que se conhecem e cultivam relações mediadas pelo afeto.

Esta investigação começou em 2012, quando adentramos o universo multicultural do bairro das Rocas para compreender como o samba nasceu e perdurou na história do lugar. Nessa caminhada, tivemos como guia o mestre Zorro, sambista e compositor, morador do bairro, onde cresceu embalado ao som de música popular brasileira e dos tambores do seu avô, entidade do candomblé. Zorro nos apresentou com maestria as raízes do samba potiguar. Assim, de forma compartilhada, construímos um arquivo de fatos e entrevistas sobre a história do samba nas Rocas. Em nosso projeto, os moradores se tornaram cúmplices na construção da história do samba do lugar; e quando chegou o momento de finalizá-lo, sentimos imensa vontade de recomeçar o trabalho. Essa história é movente, depende de quem a conta e de que perspectiva estão as pessoas que a conta. Sem dúvida, mesmo imersos na cotidianidade do lugar, percebemos o que Hall (2003, p. 44) nos afirma:

A cultura não é apenas uma viagem de redescoberta, uma viagem de
retorno. Não é uma "arqueologia". A cultura é uma produção. Tem a sua
matéria-prima, os seus recursos, o seu "trabalho produtivo". Depende de
um conhecimento da tradição enquanto "o mesmo em mutação" e de um
conjunto efetivo de genealogias. Mas o que esse desvio através dos pas-
sados faz é capacitar-nos, através da cultura, a produzir-nos a nós mes-
mos de novo, como novos tipos de sujeitos. Portanto, não é uma questão
do que as tradições fazem de nós, mas do que nós fazemos das tradições.

Cada qual se lembra de cenários construídos em seu afetivo e memória afetiva. Muitas vezes guiados pelo arquivo fotográfico guardado no tempo, capitulamos os espaços e tempos vividos. Durante a transcrição das falas, verificamos conexões importantes, criando-se uma pré-montagem do tempo passado. Segundo a pesquisadora argentina Beatriz Sarlo (2007, p. 52):

O narrador que lembra de modo exaustivo seria incapaz de passar por alto o importante, nem forçá-lo, pois o que narra formou um desvão pessoal da sua vida, e são fatos que ele viu com os próprios olhos. Num testemunho, jamais os detalhes devem parecer falsos, porque o efeito de verdade depende deles, inclusive de sua acumulação e repetição.

Os atos de cuidar de cada depoimento e estruturar cada relato como quem lapida a história de vida de cada ser interligado ao lugar resultaram em dois documentários - As mulheres das Rocas são as vozes do samba (20 min, 2015) e Mestre Zorro (20 min, 2016) também em um CD de compositores das Rocas. O CD Mestre Zorro e o samba canguleiro foi gravado no Beju Estúdio em Natal, com dez músicas autorais de compositores ligados ao samba do bairro das Rocas, sob a direção técnica de Jubileu Filho. Na produção do CD descobrimos que o 136 número de composições de mestre Zorro ultrapassava duzentas criações, todas com associações incríveis da história do Brasil, das Rocas e da cidade de Natal.

Ao buscar materiais sobre o samba nas Rocas em arquivos públicos, editoras independentes, livrarias e arquivos de trabalhos científicos, percebemos que não havia muito material. Há ausência nas pesquisas e desconhecimento sobre o assunto. Esse vazio histórico reflete certo preconceito com relação ao universo do samba das Rocas, que também é conhecido como samba praieiro, 
designação dos próprios sambistas nascidos no bairro, ou samba roqueiro, que faz referência a quem nasceu ali. Já comentamos que a relação entre o samba e o bairro das Rocas é estreita, secular e indiscutível. No entanto, dentro desse microcosmo, uma dinâmica urbana complexa é acionada: são redes de sociabilidade, vizinhança, amizade, parentesco, permeadas por relações de poder, trabalho e lazer. Conforme depoimento do mestre Zorro3:

\begin{abstract}
As fundações de escolas de samba está muito ligada à familia. Por exemplo, Lucarino com a Balanço do Morro e a família dele e da minha, Em Cima da Hora, ela foi fundada pela família que se chama família Belém, família Galdino que vem de uma... De vó Isabel que até teve, a gente até fez uma homenagem a ela pós-morte na avenida. A fundação, os assinantes da fundação da Em Cima da Hora são 60 a $70 \%$ dessa família que vem de vó Isabel que é a Negra Fia, Luzimario, o próprio Miguel também que era da Em Cima da Hora assinou a ata de fundação. Então esses laços de sangue do samba que eu falo tá muito ligado à família. Claro que vêm outras pessoas né.
\end{abstract}

A primeira escola que teria surgido em Natal foi a Batuque do Morro em 1930 e, depois, a Asa Branca em 1950. Em 1958 nas Rocas, surgia a Malandros do Samba, fundada na porta da Igreja Matriz Sagrada Família por Aluízio Pereira, Toinho Costureiro, João Bem-Te-Vi e Manoel Farrapo.

Em 1966, em função de dissidência nessa escola, mestre Lucarino funda a Balanço do Morro, nas ruas de areia em frente à sua casa, que mais tarde seria trazida para dentro de sua residência, na quadra mestre Lucarino (seu quintal). Em 2016, a escola Balanço do Morro trouxe para a avenida a trajetória do mestre Lucarino, com o enredo "Balanço, 50 anos de glória". Em 1990, a escola de samba Em Cima da Hora é fundada (a mais nova entre as três que estão em atividade nas Rocas), agremiação estabelecida pela família Belém.

O samba continua sendo hoje um gênero musical no qual há a predominância de homens, tanto dentro da indústria, como nos espaços onde é tocado popularmente. Mas a importância das mulheres no cenário é indiscutível. Sabe-se que o preconceito de gênero é responsável por essa invisibilidade. Mesmo protagonizando a história dessa manifestação popular, muitas cantoras, compositoras e líderes de escola de samba foram silenciadas.

A antropóloga Kelly Adriano de Oliveira (2009) afirma que tanto as mulheres quanto a religiosidade afro-brasileira tiveram papel fundamental para que o samba conseguisse resistir, porque era dentro dos terreiros das casas das tias baianas - cujo símbolo ficou marcado em Tia Ciata -, no espaço privado e escondido, que o samba podia acontecer. Não à toa, a valorização da ala das baianas nas escolas de samba é uma forma de homenagear não apenas Tia Ciata, mas a memória de todas as tias baianas do samba.

Em Natal, dona Renilda ${ }^{4}$ exerceu esse papel de anfitriã do samba local, e vários sambistas se reuniam em sua casa:

É assim minha filha, é assim. Começou aqui o samba dos meninos. Começou aqui na minha casa. Então eles viam todo final de semana, feriado eles estavam aqui, aí eu fazia muita tira gosto, muita comidinha pra eles, traziam as namoradas, até dormir aqui eles dormiam [risos]. [...] O cenário do samba naquele tempo era só aquelas coisa. Nas Rocas já tinha esses sambas. Não era como agora né que é muito bem representado. Era mas tinha pouco. Cuíca, pandeiro as coisinha assim e o percurso era ali na Deodoro mesmo, aquele carros sem capota. Era aqueles carros sem capota, cheio de serpentina confete, passeando pra lá e pra cá aí pra li olhar passava aqueles pessoal tudo, as fantasias era 
marinheiro, era umas coisa tão engraçada! Era umas fantasias tudo nem decente.

Auxiliadora complementa essa afirmação rememorando seu passado. O corso era um momento aguardado com muita alegria, e o percurso era praticamente o mesmo todos os anos, da Rádio Poti à rua Apodi, na avenida Deodoro da Fonseca, ao final da tarde. A turma jogando pó de arroz e água nas pessoas que passeavam nos carros. A festa carnavalesca era animada com o uso das serpentinas, confetes, lança-perfume, fantasias, máscaras. Segunda ela, os cortejos carnavalescos desembocavam no Largo da Feira, defronte à Igreja São Jorge, Igreja Sagrada Família. A festa acontecia nas ruas e nos clubes.

Auxiliadora $^{5}$ se orgulha de ter sido a primeira porta-estandarte do carnaval e ter participado do bloco Só Falta Você: "eu com 15 anos tinha uma escola de samba ali na turma do morro e tinha o Só Falta Você. Ai eu fui brincar, tinha a porta bandeira, mas saiu ai me chamaram para eu ir brincar, eu tinha 15 anos, aí eu fui e ainda brinquei 2 anos". Ela diz:

Eu brinquei muito, era bom naquele tempo, visse! A gente brincava sem medo andava sozinha de noite por aqui a fora não tinha quem bulisse com a gente nem com ninguém [...] era tudo legalzinho. Hoje em dia não, tá tudo mudado. Aí eu fiquei velha e fui brincar nos Malandros de Baiana porque já tava velha e botei minhas meninas tudinha para brincar lá, brincaram na comissão de frente e a escola que a gente brincava naquele tempo não tinha comissão de frente nem nada não era baliza - baliza era aquela moça do pauzinho que rodava assim e ia de uma ponta a outra - e tinha o mestre-sala e a porta-bandeira e as meninas que brincava era tudo nas alas tudinho de roupa cumprida, não tinha nenhuma de roupa curta, de roupa curta era só a porta-bandeira e a baliza, bem curtinha.

Apesar da segregação espacial e social ser pouco acentuada na fala das entrevistadas, observamos nas narrativas camufladas sua fragmentação. Enquanto a maioria da população mais pobre brincava nas ruas com troças e pequenos blocos, a elite se divertia com o corso e nos clubes sociais. Essas manifestações já traziam a segregação e o preconceito com a população pobre e negra.

Como afirma Beatriz Sarlo (2007), cada biografia é uma articulação de pequenas histórias, pequenos detalhes que dão sentido ao passado. A autora nos convida a fazer uma análise crítica de cada experiência; para ela, "esses discursos testemunhais, sejam quais forem, são discursos, e não deveriam ficar confinados numa cristalização inabordável” (Ibid., p. 47).

São muitas as histórias para contar, alegrias, delicadezas, sustos e dilemas. No caso de Dorinha e Leda, mulheres certas de suas escolhas, que venceram o preconceito em uma época machista: fugiram para se casar com sambistas, que eram os baluartes do samba. Dorinha se casou com mestre Lucarino; e Leda, com mestre Melé. Nunca foram para a avenida sambar. Dorinha é presidente de honra/vitalícia da Balanço do Morro, enquanto Leda foi a primeira mulher "puxadora"6 de escola de samba de Natal, da Malandros do Samba.

Dorinha $^{7}$, viúva, narra como fugiu e enfrentou a família na época: "Quando fui morar com ele me entreguei à escola e aos seus afazeres na escola. [...] A Balanço do Morro é um filho nosso. Eu amo a escola. Não tanto como meus filhos, mas ela é um pedacinho de mim".

Leda ${ }^{8}$, ainda muito triste com a perda do marido, se emociona ao narrar quando viu pela primeira vez aquele que seria o pai de seus filhos. Foi num evento no Ginásio de Esporte ligado ao samba, ela ficou encantada com a figura 
de um "homem todo de branco, com cabelos prateados que comandava o ritmo da bateria e das mulatas".

Leda nasceu no interior e veio morar ainda muito jovem com a tia em Natal, e também fugiu para morar com seu esposo. Quando se conheceram, ele fez a seguinte pergunta: "Você tem uma rede?", e foi o suficiente para ela se aventurar no mundo desconhecido, que segundo ela lhe deu muita alegria.

Dalva $^{9}$ sempre gostou de brincar no carnaval e usar roupas curtas. Ela é uma foliã e escolheu a escola Malandros do Samba, casou-se com Erivaldo, carnavalesco da escola rival, Balanço do Morro, e permanece fiel à sua escola até hoje. Segundo ela, "naquele tempo quem usava roupa curta era muito visada, $e$ eu sempre gostei do bom e do melhor". Dalva também afirma que "carnaval é uma família, é uma família pra quem gosta de pular carnaval".

Dalva salienta algo que foi notado durante a pesquisa - que eles são uma "família", muitos são parentes consanguíneos ou não. Mas há tensões que são abrandadas nas relações afetivas de vizinhança e companheirismo.

Dorinha $^{10}$ nos conta sobre seu marido, Lucarino Roberto de Souza, o fundador da escola Balanço do Morro: "Lucarino tinha dom de liderança e o que ele queria era atendido. Naquela época todo mundo trabalhava por amor, não era por dinheiro não". Ela narra com detalhes o protagonismo de Lucarino no samba natalense; ele foi sambista, compositor, dramaturgo e líder local. Segundo ela, as dificuldades enfrentadas foram muitas, como a manutenção da escola, a dificuldade de conseguir material de construção para ampliação, as pequenas reformas etc.: " as meninas sambavam na areia que vinha da praia, e Lucarino pediu o calçamento da rua para o prefeito para as meninas ensaiarem de salto alto. O samba tá no sangue".

O depoimento de Auxiladora nos comoveu e nos fez refletir sobre o respeito que o pesquisador deve ter ao que o outro tem a dizer. São histórias dentro de outras histórias que nos mostram como a vida é cheia de nuances, silêncios, sutilezas e dor.

Mulher, eu tinha nove filhos. Morreu a mais velha, morreu faz sete anos. Agora dia primeiro de outubro morreu dois filhos meus num dia só: um que era sargento da aeronáutica e o outro não era não, era... Tinha marca-passo. Todos dois foram do coração. O sargento morreu na mesa de cirurgia e o outro morreu à tarde, um morreu de manhã e o outro morreu de tarde. Aí fiquei só com seis. Neto eu não vou contar nem quantos têm porque essas meninas ai todo ano, todo dia tem menino.

Retomamos o depoimento de dona Renilda, considerada a "mãe Ciata" do bairro das Rocas, todos os sambistas a mencionam como a mais velha senhora do samba das Rocas. A sua história pessoal é um bordado que alinhava todas as outras histórias do bairro. Dona Renilda, nascida em Canguaretama, chegou a Natal em plena Revolução Comunista de 1935. O depoimento de dona Renilda nos levou para diferentes "temporalidades", com episódios relacionados à Revolução Comunista de 1935 e à Segunda Guerra Mundial.

Eu ainda sou desse tempo. Teve essa revolução aqui em 1935 quando eu vim pra cá. Eu sou de Canguaretama, vim aqui pra Natal com três anos de idade mas me lembro de tudo [...] Bom a gente vinha... O meu pai separou da minha mãe, ai veio para Natal para se casar com uma moça que ele roubou, trouxe a moça roubada e eu e a minha irmã. A minha mãe tava grávida do meu irmão que morreu. Ai quando a gente chegou aqui em Natal já de noite, de trem, tava uma revolução, nem descemos do trem, dormimos no vagão do trem. Que as balas passava por cima, eu era pequena, mas eu lembro. Então deixamos passar a 
noite, no outro dia a gente foi procurar a casa ali na Guarita. O trem ficou ali na Guarita e a gente morou na Guarita. Meu pai arrumou a casa e ficou morando lá e foi casar.

\section{E continua:}

Não tinha esse de gelar os peixes era tudo fresquinho no sangue, e a gente comia um peixe cozido. Agora ninguém mais sente gosto de peixe nem nada, bacalhau era comida de preso. Hoje em dia só come quem tem dinheiro. Quando a gente via um cheiro de bacalhau assim assando nas casas, a gente sabia que eram as pessoas bem pobrezinha é que não tinha o que comer e comia bacalhau. Era aquelas barricas assim bem grande cheia de bacalhau, era o tira-gosto dos papudinhos.

Relembrar um tempo traz consigo todas as imagens ali vividas. As experiências se estendem além do individual. O samba chega depois na vida de Renilda, que nos conta sobre uma época de dificuldades, permeada com revolução e guerra. A existência de Renilda, somada a dos outros, compõe uma história coletiva das Rocas, com significados sociais, políticos, culturais e econômicos muito mais amplos.

As entrevistas gravadas em profundidade pressupõem também um envolvimento, uma imersão. Escutar não é induzir as pessoas a dizer o que gostaríamos de ouvir; também não é interrompê-las quando não falam com a clareza esperada. Por essa razão, as conversas foram realizadas em vários encontros e tudo dependia da intensidade delas. Muitas vezes íamos de três a seis vezes ao mesmo depoente. Quem fala é que determina o tempo e, às vezes, precisa de um período maior para poder construir sua memória. Esse tempo também é necessário para que encontrem fotos e recortes de jornais guardados. Tudo é condicionado em caixas de sapatos e gavetas, como arcas que guardam tesouros em imagens e textos, que tecem histórias importantes do samba e da comunidade.

Em uma das casas, uma antiga vitrola com vinil tocava um samba-enredo longínquo da escola Balanço do Morro. Os moradores tiveram esse cuidado para nos recepcionar. Além da música, mostraram antigos LP e as letras das canções; e cantaram junto com afinação esplêndida. Foi um momento memorável para nossa pesquisa - a sensação era de que eles sabiam que estávamos construindo de forma partilhada a história do bairro interligado com o samba. O samba une todos os moradores das Rocas e é desta forma que se reconhecem e se referenciam. Quando perguntamos onde moram, sempre usam as quadras das escolas de samba para nos orientar na cartografia do lugar.

Muitas vezes perguntamos para as antigas sambistas de Natal de onde elas eram, elas batiam no peito e diziam: “Eu sou roqueira, minha filha!”. Há um orgulho intrínseco de pertencer ao bairro das Rocas e ao samba. Os depoimentos dos antigos moradores trazem essa afirmação de pertencimento.

A história de um lugar só é estabelecida a partir dos que vivenciaram os acontecimentos, sentiram as transformações do samba e do carnaval e compreendem a organização e a sociabilidade do espaço onde estão sendo construídas há muito tempo as agremiações do samba.

Esse encontro permitiu realizar uma reflexão a respeito das narrativas e das memórias. Afinal, quem conta sua história reconstrói sua memória, percebe a dimensão do que realizou e reafirma a capacidade de decidir e participar do percurso de um lugar. Ao compartilhar seu depoimento, toma consciência do contexto maior em que está inserido. Sua história se une a dos outros, e isso entrelaça e forma a narrativa de um lugar. 
A memória emerge de um grupo que ela une, o que quer dizer, como Halbwachs o fez, que há tantas memórias quantos grupo existem; que ela é, por natureza, múltipla e desacelerada, coletiva, plural e individualizada. A história, ao contrário, pertence a todos e a ninguém, o que lhe dá uma vocação para o universal. A memória se enraíza no concreto, no espaço, no gesto, na imagem, no objeto. A história só se liga às continuidades temporais, às evoluções e às relações das coisas. A memória é um absoluto e a história só conhece o relativo. (NORA, 1993, p. 9)

A citação acima fertiliza a construção de documentários que utilizam a história oral e o documentário de imersão no resgate das memórias dos lugares. A memória é algo absoluto e há muita fragilidade e vontade na voz dos que não são escutados habitualmente. Quando descobrem que têm um canal para reverberar suas memórias, sentem-se comprometidos em cuidar da história de todos. É necessário assumir a responsabilidade pelo que é frágil.

\section{DE QUE LADO VOCÊ SAMBA? REFLEXÕES EM TORNO DA PRODUÇÃO AUDIOVISUAL COMPARTILHADA}

A pesquisa com uso de imagem nas Ciências Humanas não é só uma estratégia de captação de dados e ilustração do contexto, mas também uma construção conceitual e de interpretação da realidade social no momento da ação. Sabe-se que a imagem fugiu sempre da característica única e limitadora de "objeto disciplinar" e exigiu tratamento nos limites alargados da transdisciplinaridade.

A busca de novas perspectivas teórico-metodológicas é feita pelo questionamento da tendência em construir o conhecimento coletivo utilizando a dimensão imagética como documento da "realidade objetiva", ao invés do simples registro e da documentação visual do "instantâneo da experiência". Existe uma importância de dedicar maior atenção aos significados culturais engendrados pelas narrativas e imagens, bem como às formas pelas quais a produção e a leitura dessas imagens são mediadas. $\mathrm{O}$ audiovisual é pensado como instrumento provocativo que altera as relações entre os sujeitos filmados e o sujeito que filma.

Atualmente há uma nova tendência de construir conhecimento a partir das imagens que apresentam fotografias, filmes, sons e desenhos em suas etnografias. Segundo Novaes (2008, p. 463), “o mundo de hoje é, cada vez mais, um mundo de imagens e de interatividade. A antropologia até pouco tempo tinha sido, predominantemente, uma disciplina de palavras: uma disciplina na qual se fala, sobre a qual se escreve, e que se lê". Atinente a estes aspectos, Clarice Peixoto (1999) revela, através de suas experiências, como apresentar cinematograficamente os resultados de uma pesquisa. Rocha e Eckert (2013) propõem uma etnografia da duração nas etnografias urbanas; Hijiki e Caffé (2014) dizem sobre a "ausculta audiovisual" na produção audiovisual, e Ana Lúcia Ferraz (2010) discute a noção de tempo nos filmes etnográficos. No culminar desta discussão, a proposta de Trinh T. Minh-ha (1991) com seus polêmicos filmes experimentais contribui para o projeto de revisão da crítica da representação e da autenticidade.

Essas novas estratégias metodológicas podem criticar os postulados da autoridade acadêmica que estão, na maioria das vezes, atrelados a um conceito positivista de cientificidade. Ou seja, trazem em suas proposições o paradigma tradicional do texto escrito como única fonte geradora de conhecimento, domesticando o olhar através de paradigmas teóricos. Como alerta Boaventura Souza Santos (1987), uma das formas de pensar a globalização contra-hegemônica é conhecer modos alternativos de pensar, bem como valorizar diferentes formas de conhecimento e visões de 
mundo, que podem ser reconhecidas se tomarmos uma atitude de multiculturalismo ativo e progressista. Igualmente, por fazer parte de uma proposta de revisão crítica dos próprios cânones científicos, cabe a reflexão sobre novos instrumentais para entendermos as dinâmicas contemporâneas e contribuirmos para a formação de um conhecimento crítico, interdisciplinar e socialmente engajado.

Como apontam Rocha e Eckert (2013, p.127) com relação às críticas que rondam as técnicas e teorias antropológicas: "não se trata de destruir uma ordem científica estabelecida, mas de 'desconstruir' a ordem para melhor avaliar nossos papéis na construção de uma temporalidade mais humanitária”.

O processo de produção desse documentário nos levou a refletir sobre uma etnografia da duração na produção audiovisual, a importância da escuta e de prestar atenção a cada gesto, trejeito, olhar. É preciso registrar nova temporalidade e não perder nada, tentar chegar mais perto da maneira que as pessoas se expressam. Cada uma delas, com seus afetos e desafetos, são mulheres felizes, batalhadoras, interessadas, atentas e gentis. Um leque imenso de conhecimentos que marcam qualquer trajetória, independente do tempo que passam em nossas vidas.

É importante retomar a discussão sobre narrativas, aparentemente uma questão ultrapassada, mas que sempre suscita novas abordagens. Percebemos na cidade diferentes tradições narrativas, o morador se reinventa como sujeito ao narrar. São suas lembranças, seus afazeres, seus ofícios e itinerários, que quando acionados possibilitam impulsionar o jogo da memória que consolida o viver.

\section{CONSIDERAÇÕES FINAIS}

Nossa percepção sobre o cenário do samba foi aprimorada no contato diário com nossos interlocutores, que nos distanciou das narrativas das matérias de jornais e das crônicas sociais e nos fez desconstruir feições romantizadas que ganham destaque na época do carnaval. A maioria da população natalense desconhece a história das Rocas e toda a história atrelada ao espaço/lugar do samba e de suas agremiações.

Observamos que o bairro tem uma estética urbana particular, pautada no movimento das ruas, feiras, mercados, lugares de convivência, das sociabilidades nas esquinas, que conferem diferentes sentidos e ritmos ao bairro. Os encontros ligados ao samba nem sempre são planejados, mas seguem um itinerário entre o Bar da Naná, Bar do Jonas, Racing Sport Club, churrascos de rua e pequenos bares onde se compartilham subjetividades e memórias do viver urbano. Apesar da disputa acirrada entre as escolas de samba durante o carnaval, os componentes das agremiações interagem durante o ano todo nas rodas de samba, lançamentos dos sambas-enredo, feijoadas beneficentes e demais atividades.

No documentário registramos essa movimentação dos integrantes em diferentes escolas, e os membros da Balanço do Morro prestigiando o lançamento do samba-enredo da Malandros do Samba. De fato, surpreendemos com os estreitos laços de consanguinidade, vizinhança e amizade presentes no bairro. A confiança e a afinidade são valores importantes entre os moradores, que cultivam 142 vínculos de reciprocidade e ajuda mútua. Isso é perceptível no compartilhamento das informações diárias via WhatsApp, na alimentação nas rodas de samba e nos deslocamentos da casa para o samba.

A roda de samba no Racing Club acontece por iniciativa de um compositor, que convida os demais colegas, e de repente aparecem vizinhos, crianças e moradores do bairro. O Racing tornou-se ponto de encontro de todos os sambistas das Rocas. Atualmente estão reativando outro clube como mais um lugar 
do samba, o Palmeiras, localizado próximo à Igreja Sagrada Família, a partir da iniciativa de Rogerinho (filho do Lucarino, fundador da Balanço do Morro).

Para concluir, retomamos a situação relatada por Dalva, que casou com um carnavalesco da escola rival, mas até hoje é foliã do Malandro do Samba. E como nos ensina mestre Zorro: "o samba nas Rocas sempre foi participativo".

No entanto, o bairro das Rocas continua sendo estigmatizado, carregando estereótipos de violência e desordem, historicamente atribuídos aos espaços populares. Sabemos que os estereótipos são sempre acompanhados de preconceitos. Durante essa pesquisa, defrontamos com questões de gênero e raça/etnia e observamos como essa combinação aponta para práticas discriminatórias da sociedade contemporânea. $\mathrm{O}$ preconceito com relação às mulheres negras, às passistas e às cantoras ainda existe. A invisibilidade é o testemunho desse preconceito.

Acreditamos que o audiovisual possa ser um meio de mobilizar pessoas e descontruir estigmas e estereótipos. Neste contexto, sublinhamos a importância de uma reflexão intensa sobre o processo de imersão em campo, a construção das narrativas, o compromisso ético e a produção de conhecimento com imagens.

A construção de documentários compartilhados sobre a história de um lugar pode colaborar com a circulação da arte existente. Este trabalho foi muito importante para os moradores das Rocas - hoje se veem como importantes detentores da história. $\mathrm{O}$ alcance da repercussão dessas imagens na vida dessas pessoas, no bairro e na cidade foi extremamente gratificante, bem como pensar nos alcances e limites de antropologia compartilhada. Esperamos com esses documentários abrir novas possibilidades e novos olhares sobre o samba em Natal.

\section{NOTAS}

1. Mestre Zorro, entrevista pessoal n. 1, realizada em 11 de março de 2012.

2. O Projeto Narrativa Memória e Itinerário é coordenado pelas professoras Lisabete Coradini (Departamento de Antropologia da UFRN) e Maria Angela Pavan (Departamento de Comunicação Social da UFRN) e conta com oito alunos bolsistas e voluntários. É uma parceria entre os grupos de pesquisa NAVIS-UFRN (Núcleo de Antropologia Audiovisual) e PRAGMA-UFRN (Pragmática da Comunicação e da Mídia). Congrega pesquisadores, professores, alunos da graduação e pós-graduação em Antropologia e Comunicação Social.

3. Mestre Zorro, entrevista pessoal n. 2, realizada em 15 de maio de 2013.

4. Dona Renilda, entrevista pessoal n. 1, realizada em 15 de maio de 2013.

5. Auxiliadora, entrevista pessoal n. 1, realizada dia 15 de agosto de 2013.

6. Puxador de samba ou puxadora de samba são cantores que têm a voz principal no desfile da escola de samba no carnaval.

7. Dorinha, entrevista pessoal n. 1, realizada em 20 de agosto de 2013.

8. Leda, entrevista pessoal n. 1, realizada em 10 de março de 2015.

9. Dalva, entrevista pessoal n. 1, realizada em 5 de setembro de 2014.

10. Dorinha, entrevista pessoal n. 2, realizada em 11 de agosto de 2014.

\section{REFERÊNCIAS}

FERRAZ, Ana Lúcia Marques Camargo. A experiência da duração no cinema de Jean Rouch. Doc On-line: Revista Digital de Cinema Documentário, Lisboa; São Paulo, v. 8, p. 80-112, ago. 2010. Disponível em: <https://goo.gl/b5XUjB>. Acesso em: 4 dez. 2017.

HALL, Stuart. Da diáspora: identidades e mediações culturais. Belo Horizonte; Brasília, DF: UFMG; Unesco, 2003. 
HIJIKI, Rose Satiko Gitirana; CAFFÉ, Carolina. A arte e a rua: audiovisual ethnography on the outskirts of São Paulo. Alter/nativas: Latin American Cultural Studies Journal, Columbus, n. 2, p. 1-15, 2014.

MACDOUGALL, David. Transcultural cinema. Princeton, NJ: Princeton University Press, 1999.

MAGNANI, José Guilherme Cantor. De perto e de dentro: notas para uma etnografia urbana. Revista Brasileira de Ciências Sociais, São Paulo, v. 17, n. 49, p. 11-29, jun. 2002.

MESTRE Zorro. Direção de Lisabete Coradini e Maria Angela Pavan. Natal: Navis; Pragma; UFRN; Proext, 2016. $20 \mathrm{~min}$.

MINH-HA, Trinh. When the moon waxes red:. representation, gender and cultural politics. London; New York: Routledge, 1991.

AS MULHERES das Rocas são as vozes do Samba. Direção de Lisabete Coradini e Maria Angela Pavan. Natal: Navis; Pragma; UFRN; Proext, 2015. 25 min.

NORA, Pierre. Entre memória e história: a problemática dos lugares. Projeto História: Revista do Programa de Estudos Pós-Graduados de História, São Paulo, v. 10, p. 7-28, dez. 1993.

NOVAES, Sylvia Caiuby. Imagem, magia e imaginação: desafios ao texto antropológico. Mana, Rio de Janeiro, v. 14, n. 2, p. 455-475, out. 2008. Disponível em: <https://goo.gl/QLVSuF>. Acesso em: 4 dez. 2017.

OLIVEIRA, Kelly Adriano. Deslocamentos entre o samba e a fé: um olhar para gênero, raça, cor, corpo e religiosidade na produção de diferenças. 2009. 252 f. Tese (Doutorado) - Universidade Estadual de Campinas, Campinas, 2009.

PEIXOTO, Clarice Ehlers. Antropologia e filme etnográfico: um travelling no cenário literário da antropologia visual. $B I B$ : Revista Brasileira de Informação Bibliográfica em Ciências Sociais, Rio de Janeiro, n. 48, p. 91-116, jul./dez. 1999.

ROCHA, Ana Luiza Carvalho; ECKERT, Cornélia. Etnografia da duração: antropologias das memórias coletivas nas coleções etnográficas. Porto Alegre: Marcavisual, 2013.

ROUCH, Jean. The camera and man. In: HOCKINGS, Paul (Ed.). Principles of visual anthropology. New York: Mouton de Gruyer, 1995. p. 79-98.

SANTOS, Boaventura de Sousa. Um discurso sobre as ciências. Porto: Afrontamento, 1987.

SAMAIN, Etienne (Org.). Do fotográfico. São Paulo: Hucitec, 1998.

SARLO, Beatriz. Tempo passado, cultura da memória e guinada subjetiva. São Paulo; Belo Horizonte: Companhia das Letras; UFMG, 2007.

144 SEU Pernambuco. Direção de Lisabete Coradini e Maria Angela Pavan. NAVIS/ PRAGMA/UFRN, Proext, 2015. $8 \mathrm{~min}$.

SEVERIANO FILHO, Valdemiro. Índios carnavalescos: juntos e misturados na folia natalense. Rio de Janeiro: Planeta Azul, 2014.

SODRÉ, Muniz. As estratégias sensíveis: afeto, mídia e política. São Paulo: Vozes, 2006 